\title{
Arterial stiffness in patients with coronary artery disease: relation with in-stent restenosis following percutaneous coronary intervention
}

Zrinko Prskalo ${ }^{1}$, Ivica Brizić ${ }^{*}$, Darko Markota ${ }^{1}$, Ivica Markota ${ }^{1}$, Mladen Boban ${ }^{3}$, Monika Tomic ${ }^{2}$ and Boris Starcevic ${ }^{4}$

\begin{abstract}
Background: Coronary artery disease (CAD) is one of the most important issues in modern medicine due to its high mortality and prevalence. An early detection and prevention can reduce morbidity and mortality. Arterial stiffness is a potent and independent predictor of CAD. We aimed to investigate the arterial stiffness in CAD patients undergoing the coronary angiography. Also, we investigated a possible correlation between arterial stiffness and in-stent restenosis (ISR), an important limitation of percutaneous coronary intervention (PCI).
\end{abstract}

Methods: The study included 160 patients undergoing coronary angiography, treated either with PCI or with CABG. The pulse wave velocity (PWW) and augmentation index (Alx) were measured by the Arteriograph.

Results: PWV in the CAD group $(12.24 \pm 2.78 \mathrm{~m} / \mathrm{s})$ was significantly higher compared to the control group $(8.27 \pm 1.89 \mathrm{~m} / \mathrm{s})$. PW in ISR and left main (LM) stenosis group $(14.03 \pm 3.15$ and $13.89 \pm 2.95 \mathrm{~m} / \mathrm{s})$ was significantly higher compared to the control and CAD groups. Peripheral and central Alx were significantly higher in CAD group $(1.38 \pm 30$. $63 \%$ and $38.35 \pm 15.52 \%)$ than in control group $(-11.35 \pm 26.74 \%$ and $26.91 \pm 10.62 \%)$. Patients with LM stenosis have significantly higher values of peripheral and central Alx $(23.37 \pm 23.77 \%$ and $49.71 \pm 12.02 \%)$ than the CAD and ISR group.

Conclusions: The study confirmed a positive correlation between arterial stiffness measures, PWV and Alx, and CAD. Also, this study showed the correlation between PWV and ISR which can help to select more appropriate stent.

Keywords: Vascular stiffness, Coronary artery disease, Coronary restenosis

\section{Background}

Coronary artery disease (CAD) is one of the most important issues in modern medicine due to high prevalence and mortality. Both, the prevention and treatment of CAD in recent decades have been improved, however, CAD remains the first inductor of morbidity and mortality in humans [1]. An early detection and prevention of CAD is very important and can reduce morbidity and mortality. Numerous epidemiological and clinical studies showed a positive correlation between $\mathrm{CAD}$ and male gender, high blood pressure, diabetes, smoking, physical inactivity,

\footnotetext{
* Correspondence: ibrizic@gmail.com

'Department of Cardiology, University Hospital Mostar, Bijeli Brijeg bb, 88000 Mostar, Bosnia and Herzegovina

Full list of author information is available at the end of the article
}

and hyperlipidemia [2]. In addition to these traditional risk factors, the arterial stiffness defined as a direct measure - aortic pulse wave velocity (PWV) and an indirect parameter - augmentation index (AIx), is a strong and independent predictor of CAD and adverse cardiovascular events $[3,4]$. The majority of the current research, investigating correlation between arterial stiffness and CAD was of observational or epidemiological nature $[5,6]$. Only few clinical studies showed a direct correlation between PWV and CAD diagnosed by coronary angiography $[7,8]$.

Treatment of CAD could involve pharmacotherapy, percutaneous coronary interventions (PCI), and surgical revascularization. All methods are associated with some limitations and disadvantages. In the past few decades 
the development of PCI, atherectomy, with bare-metal (BMS) and drug eluting stents (DES) has made a significant progress in the management of CAD [1]. The most important limitation of $\mathrm{PCI}$ is thrombosis and in-stent restenosis (ISR). The incidence of ISR after a BMS implantation is $20-25 \%$ in the first 6 months [9]. The development of DES contributed to a significant reduction of the ISR, as it decreased the incidence rate of ISR in only $5-10 \%$ cases [10-12]. However, the rate of DES use is lower than $10 \%$ in most countries due to the high cost. The incidence of DES implantation in developing countries, such as ours, is smaller than an average rate, because of its higher cost.

Factors that contribute to ISR are not fully understood. Cassese et al. showed that diabetes mellitus, multiple lesions, small vessels, multiple stents, smaller final stent lumen diameter and stent design are predictors for ISR $[11,13]$. Some previous studies established a link between arterial stiffness and ISR. Ueda et al. found a correlation between AIx in the ascending aorta and ISR [14]. Also, Nakayama et al. showed a correlation between pulse pressure and ISR [15]. Recently, Mahfouz et al. described a correlation between arterial stiffness measured with ultrasonography and ISR [16].

In this study we aimed to investigate the correlation between $\mathrm{CAD}$ assessed by coronary angiography graded by SYNTAX score and arterial stiffness measured by Arteriograph, a simple, inexpensive, reproducible and investigatorindependent method. Also, we investigated the correlation between ISR and aortic PWV and Aix.

\section{Methods}

The study included 160 patients with CAD who underwent an elective coronary angiography in the Department of Invasive Cardiology of Clinical Hospital Mostar from $1^{\text {st }}$ April 2014 to $1^{\text {st }}$ October 2014. The control group consisted of 59 sex and age-matched healthy people. All subjects in the control group underwent the clinical examination, ECG, stress test, echocardiography, measuring of arterial stiffness and laboratory testing. All those subjects had a clear medical history. The CAD group excluded subjects with atrial fibrillation, acute coronary syndrome, and with significant valvular disease. All CAD patients had previous concordant non-invasive findings for $\mathrm{CAD}$ and experienced angina pectoris. They received an appropriate treatment (statines, beta blockers, $\mathrm{ACE}$ inhibitors and aspirin) in accordance with the guidelines for CAD [17]. Out of a total number of CAD patients, 102 were treated with PCI and 58 underwent heart surgery. During the next 6 months 23 patients had ISR in BMS. All patients who underwent PCI had dual antiplatelet therapy, aspirin and clopidogrel. The study was conducted in accordance with the Helsinki Declaration and approved by the Ethics Committee of the University
Hospital Mostar. All subjects gave written informed consent to participate in this study.

\section{Coronary angiography and SYNTAX score}

All patients underwent routine coronary angiography using the Judkins technique on digitized coronary angiography equipment (Shimadzu, Kyoto, Japan). Coronary angiograms were computerized and assessed by two experienced angiographers who were blinded to the results of arterial stiffness measurements. A significant CAD was defined as at least $50 \%$ or more stenosis. ISR was defined as $>50 \%$ diameter stenosis at the stent site.

The SYNTX score is a semi-quantitative angiographic tool to determine the extent of CAD [18]. The algorithm contains of 12 questions referring to the coronary anatomy and total number and extent of coronary artery lesions. The SYNTAX score was calculated for each coronary lesion producing a $\geq 50 \%$ luminal obstruction in vessels with a diameter of $1.5 \mathrm{~mm}$ or more. Patients were divided according to 2-year rates of major adverse coronary events as low (0-22), intermediate (23-32), and high $(\geq 33)$ risk group. The SYNTAX score was calculated with a computer-based questionnaire program.

\section{Measurements of arterial stiffness}

Arterial stiffness was measured by an oscillometric non-invasive device Arteriograph (TensioMed, Budapest, Hungary). The device detects and processes oscillations on the upper-arm positioned cuff by a special high fidelity sensor during a complete occlusion of brachial artery. Simultaneously with the parameters of arterial stiffness (PWV (m/s) an AIx (\%), the device also recorded systolic and diastolic blood pressures and heart rate [19].

Twenty-four hours prior to the examination subjects were asked to refrain from exercise, fruits, vegetables, dietary supplements, tea, alcoholic beverages, and caffeine containing foods. Also, 12 hours before measurement of arterial stiffness patients did not take any drugs. All experiments were carried out in a quiet, temperature controlled room maintained around $24{ }^{\circ} \mathrm{C}$ and were started at 8 a.m. The subjects had rested quietly for $15 \mathrm{~min}$ in the supine position before the measurement.

\section{Statistics}

Data are expressed as mean \pm SD. Statistical analyses were performed using GraphPad Instat and GraphPad Prism (San Diego, CA USA). All variables were normalized before data statistical analyses on age, heart rate and blood pressure. One-way ANOVA test was used to evaluate changes in AIx and PWV. When statistical significance was reached by ANOVA $(P<0.05)$, Bonferroni test was used for the post hoc analysis. 


\section{Results}

In this study we investigated the association of arterial stiffness with CAD and correlation between degrees of CAD measured by SYNTAX score. We found a strong correlation between CAD and arterial stiffness, but no association between degrees of the CAD with the parameters of arterial stiffness. From CAD group we extracted CABG, PCI, left main (LM) stenosis and ISR groups.

The general characteristics of control, CAD, ISR and LM stenosis groups are shown in Table 1 . In the control and all experimental groups the male sex was dominant. Also, in the CAD, ISR and LM stenosis group, patients were slightly older with higher mean arterial pressure.

Aortic PWV in the CAD group $(12.24 \pm 2.78 \mathrm{~m} / \mathrm{s})$ was significantly higher compared to the control group $(8.27 \pm 1.89 \mathrm{~m} / \mathrm{s})(P<0.05)$. Also, PWV of an ISR and LM stenosis group $(14.03 \pm 3.15$ and $13.89 \pm 2.95 \mathrm{~m} / \mathrm{s})$ was significantly higher than in the control and CAD group $(P<0.05)$ (Fig. 1).

The central AIx in the CAD, ISR and LM stenosis group $(38.35 \pm 15.52,39.71 \pm 13.97$ and $49.71 \pm 12.02 \%$, respectively) was significantly higher compared to the control group $(26.91 \pm 10.62 \%)(P<0.05)$. Also, central AIx of an LM stenosis group was significantly higher than in the CAD and ISR group $(P<0.05)$ (Fig. 2$)$.

The peripheral AIx in the CAD, ISR and LM stenosis group (1.38 \pm 30.63 and $4.09 \pm 27.60$ and $23.37 \pm 23.77 \%$, respectively) was significantly higher compared to the
« Control group (n-59)
2 CAD group (n-160)
ISR group $(n-23)$
एس) Left main stenosis (n-9)

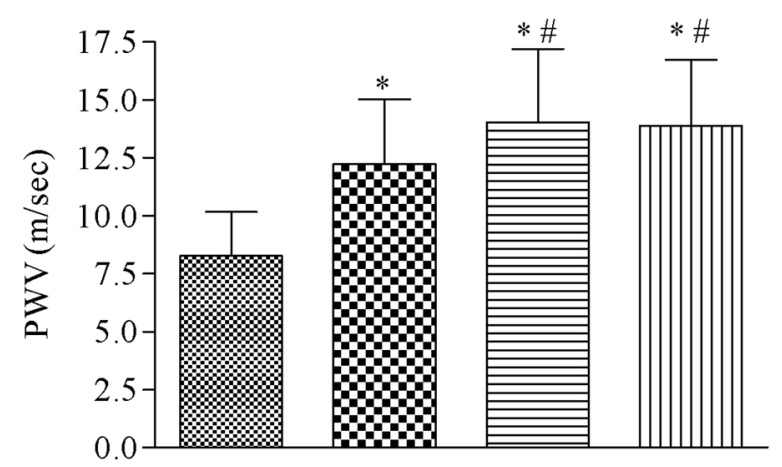

Fig. 1 The values of aortic pulse wave velocity (PWV) in the control, coronary artery disease (CAD), in-stent restenosis (ISR) and left main stenosis group. Data are shown as mean $\pm \mathrm{SD}^{*} p<0.05$ vs control group, \# $p<0.05$ vs CAD group

control group $(-11.35 \pm 26.74 \%)(P<0.05)$. Also, peripheral AIx of an LM stenosis group was significantly higher than in the CAD and ISR group $(P<0.05)$ (Fig. 3).

The SYNTAX score was significantly higher in patients who were referred for CABG and patients with LM stenosis $(34.62 \pm 12.46$ and $36.78 \pm 16.47)$ compared

Table 1 General characteristics of control, CAD and ISR groups

\begin{tabular}{lllll}
\hline & Control group $(n-58)$ & CAD group $(n-160)$ & ISR group $(n-23)$ & LM stenosis group $(n-9)$ \\
\hline Age (year) & $59.5 \pm 5.4$ & $61.5 \pm 4.8$ & $62.1 \pm 6.1$ & $63.8 \pm 8.4$ \\
Male $n(\%)$ & $43(72.9)$ & $115(71.7)$ & $22(95.7)$ & $9(100)$ \\
Female $n(\%)$ & $16(27.1)$ & $45(28.3)$ & $1(4.3)$ & $0(0)$ \\
Smoking $n(\%)$ & $21(35.6)$ & $82(51.3)$ & $8(34.8)$ & $6(66.6)$ \\
Cholesterol (mmol/L) & $5.59 \pm 1.45$ & $5.38 \pm 1.33$ & $5.06 \pm 1.56$ & $5.45 \pm 1.73$ \\
LDL (mmol/L) & $3.84 \pm 0.78$ & $3.66 \pm 0.51$ & $3.58 \pm 0.68$ & $3.78 \pm 1.44$ \\
HDL (mmol/L) & $1.02 \pm 0.43$ & $1.08 \pm 0.25$ & $1.13 \pm 0.58$ & $1.06 \pm 0.29$ \\
Triglycerides (mmol/L) & $2.12 \pm 0.91$ & $1.92 \pm 0.77$ & $1.84 \pm 0.98$ & $1.79 \pm 0.43$ \\
Heart rate (beats/min) & $65.7 \pm 6.1$ & $64.1 \pm 4,2$ & $65.1 \pm 9,7$ & $64.7 \pm 8,9$ \\
Mean blood pressure (mm Hg) & $101.3 \pm 5.6$ & $104.6 \pm 6,5$ & $105.7 \pm 8.9$ & $106.1 \pm 9.6$ \\
Diabetes mellitus $n(\%)$ & $0.0(0.0)$ & $25(15.7)$ & $3(13.0)$ & $0(0)$ \\
Glucose blood level (mmol/L) & $5.17 \pm 0.67$ & $5.71 \pm 1.73$ & $8.23 \pm 0.72$ & $5.34 \pm 0.89$ \\
Renal failure $n(\%)$ & $0.0(0.0)$ & $6(3.75)$ & $1(4.3)$ & $1(11,1)$ \\
Creatinine ( $\mu$ mol/L) & $94.22 \pm 22.96$ & $98.30 \pm 26.04$ & 143 & $109.78 \pm 32.12$ \\
SYNTAX scores & & $25.27 \pm 4.1$ & $19.33 \pm 6.9$ & $36.78 \pm 14.47$ \\
Multiple stents $n(\%)$ & $14(16.1)$ & $4(17.3)$ & $3.09 \pm 0.93$ \\
Stent diameter $(\mathrm{mm})$ & $3.01 \pm 0.78$ & $18.1 \pm 2.42$ & \\
Length of stent $(\mathrm{mm})$ & & $18.4 \pm 0.58$ & &
\end{tabular}

Data are shown as mean value \pm SD

$C A D$ coronary artery disease, $H D L$ low-density lipoprotein, ISR in-stent restenosis, $L M$ left main, $L D L$ high-density lipoprotein, $S D$ standard deviation 


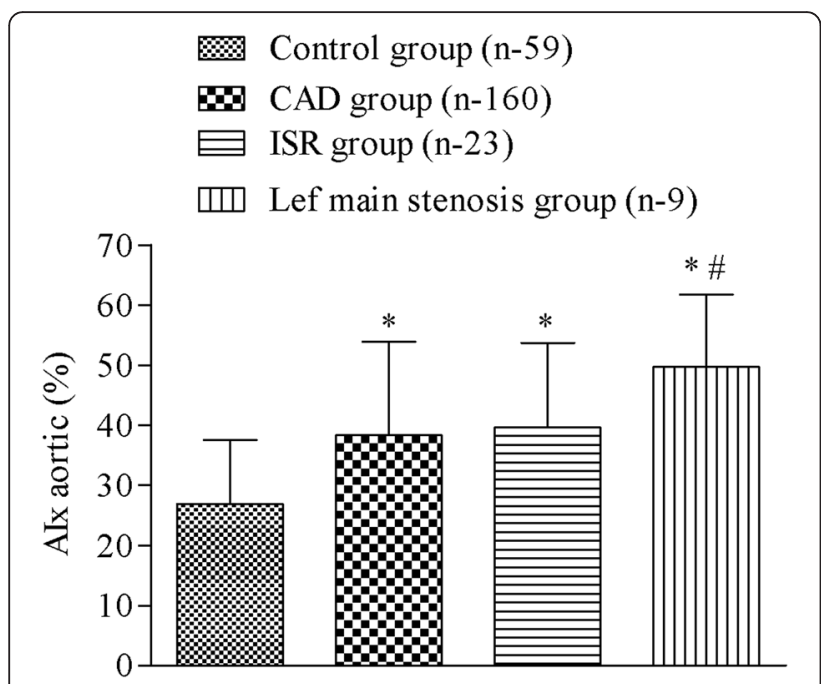

Fig. 2 The values of aortic augmentation index (Alx), expressed in percentages in the control, coronary artery disease (CAD), in stent restenosis (ISR) and left main stenosis group. Data are shown as mean $\pm \mathrm{SD}$, * $p<0.05$ vs control group, \# $p<0.05$ vs CAD and ISR groups

to the PCI and ISR group $(17.63 \pm 9.77$ and $19.33 \pm 6.9)$ $(P<0.05)$. Among patients treated with $\mathrm{PCI}$ and patients who underwent $C A B G$ we did not find a difference in the parameters of arterial stiffness (CABG vs PCI group; PWV $12.23 \pm 2.93$ vs $12.26 \pm 2.68 \mathrm{~m} / \mathrm{s}$; central Aix $37.93 \pm 14.36$ vs $38.47 \pm 15.39 \%$; peripheral AIx $1.35 \pm 28.32$ vs $1.57 \pm 30.38 \%$ ) (Additional file 1 ).

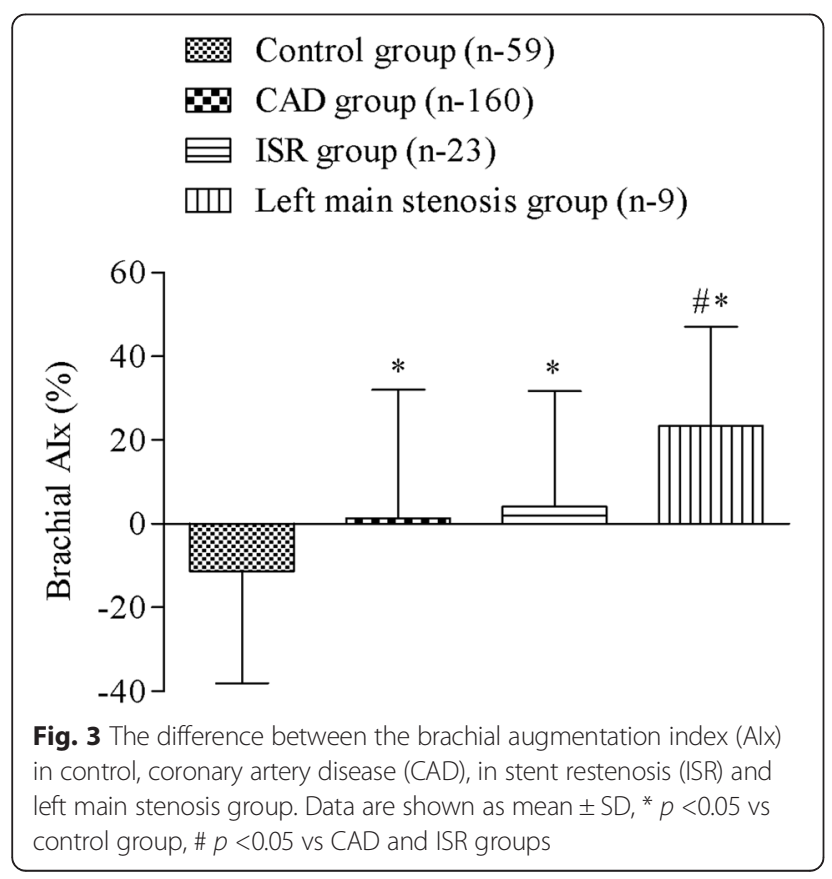

\section{Discussion}

In this study we showed a positive correlation between arterial stiffness parameters and CAD proved with coronary angiography. Also, our study showed the correlation between PWV and ISR.

Some previous studies showed the correlation between arterial stiffness and CAD [20-22]. In the most of them CAD was proved with non-invasive methods. Several studies demonstrated the correlation between CAD examined with coronary angiography and arterial stiffness. Liu et al. showed positive correlation between arterial stiffness measured by Sphygmocor and CAD proved with multi slice computed tomography coronary angiography [23]. Imanishi et al. concluded that high brachial-ankle PWV is an independent predictor for the presence of CAD, especially in men [24]. Contrary to our investigation, the arterial stiffness in the mentioned studies was proved with different devices and at different blood vessels or coronary artery disease was not identified at coronary angiography. Only one study investigated the correlation between CAD and PWV measured by Arteriograph. Similar to our study, they found the positive correlation between CAD examined with coronary angiography and arterial stiffness [7]. However, despite high differences between PWV and AIx in the control and CAD group, we also did not find the correlation between the CAD grades (defined by SYNTAX score) with PWV and AIx. But still, in this study we proved a correlation between arterial stiffness and left main stenosis. However, Cho et al. showed the correlation between AIx and the grade of CAD in patients aged less than 65 years, but not in the older ones [25]. The correlation was not found in patients above 65 years. In our opinion, it is not realistic to expect that even this method can determine the level of CAD. Also, the measuring of arterial elasticity is developed in order to asses an increased cardiovascular risk but some other specific methods should be used to confirm and prove CAD.

Furthermore, we investigated a correlation between ISR and arterial stiffness. The correlation between PWV and ISR was found, but not between AIx and ISR. Arterial stiffness is strongly dependent on the balance of two major proteins, elastin and collagen [26]. Normally, there is a tightly regulated balance between synthesis and degradation of these two proteins. Therefore, if there is an increased collagen production and reduced degradation in the whole vascular system, arterial stiffness will be increased and more likely an ISR will occur [27]. After the stent insertion some inflammatory changes in the coronary artery wall such as endothelial degradation, macrophage infiltration and smooth muscle cell proliferation could occur. Also, the inflammation in arteries increases the extracellular matrix proteins and collagen synthesis contributing to the ISR [28, 29]. BMS causes 
neointimal hyperplasia after implantation and leads to ISR and reintervention in more than $20 \%$ of patients by 6 months $[10,11]$. Similarly to our study, Ueda et al. showed the correlation between aortic stiffness and restenosis after balloon angioplasty [30]. However, mechanisms including collagen turnover in ISR and restenosis after balloon angioplasty are different. Stenting causes an even greater increase in collagen accumulation compared with balloon angioplasty [28, 31, 32]. Accordingly, the same author showed the correlation between aortic AIx and ISR [14], although the correlation between Aix and ISR was not found in our study. Recently, Mahfouz et al. proved the association of ISR and arterial elasticity [16]. All studies that have found a correlation between the extent of ISR and arterial stiffness were performed with various devices and methods. All results can contribute to a better understanding of ISR and help to make a decision considering stent implantation. In the cases of high PWV and other risks factors for ISR a cardiologist may be guided to implant DES. Moreover, this could be very useful in a cath lab with limited finances.

\section{Conclusion}

Our results confirm the importance of measuring arterial elasticity in patients with CAD predisposition. Also, we have found that an elevated PWV is associated with ISR suggesting its measuring before the procedure which contributes for a better selection of the stent implant. This study confirms the value of Arteriograph in cardiovascular risk assessment as a broadly applicable method for screening the general population.

\section{Additional file}

Additional file 1: The study data. (XLSX $16 \mathrm{~kb})$

\section{Abbreviations}

ACE, angiotensin-converting-enzyme; Alx, augmentation index; BMS, baremetal stent; $C A B G$, coronary artery bypass graft; $C A D$, coronary artery disease; DES, drug eluting stent; ISR, in-stent restenosis; LAD, left anterior descending artery; LM, left main; $\mathrm{PCl}$, percutaneous coronary intervention; PW, pulse wave velocity

\section{Funding}

This work was supported by the grant from the Ministry of Science, Education, and Sports of the Federation of Bosnia and Herzegovina.

\section{Availability of data and materials}

The datasets supporting the conclusions of this article are included within the article and its additional supplementary files.

\section{Authors' contributions}

ZP contributed to the study design, analysis and interpretation of data, drafting manuscript, and made coronary angiographies. IB contributed to the study design, data collection, analysis and interpretation of data, drafting manuscript, and made coronary angiography. DM made coronary angiographies and SYNTAX score. IM made coronary angiographies and PWV measurements. MB was involved in drafting the manuscript and revising it critically for important intellectual content. MT participate in the design of the study and performed the statistical analysis. BS made coronary angiography and SYNTAX score. All authors critically revised the manuscript and added important intellectual content. All authors read and approved the final manuscript.

\section{Competing interests}

The authors declare that they have no competing interest.

\section{Consent for publication}

Not applicable.

\section{Ethics approval and consent to participate}

The study was conducted in accordance with the Helsinki Declaration and approved by the Ethics Committee of the University Hospital Mostar. All subjects gave a written informed consent to participate in this study.

\section{Author details}

'Department of Cardiology, University Hospital Mostar, Bijeli Brijeg bb, 88000 Mostar, Bosnia and Herzegovina. ${ }^{2}$ Department of Nephrology, University Hospital Mostar, Mostar, Bosnia and Herzegovina. ${ }^{3}$ Department of Pharmacology, University of Split, Split, Croatia. ${ }^{4}$ Department of Cardiology, University Hospital Dubrava, Zagreb, Croatia.

Received: 22 November 2015 Accepted: 30 May 2016

Published online: 06 June 2016

References

1. Bonnefoy E, Kirkorian G. Mortality of myocardial infarction. Ann Cardiol Angeiol (Paris). 2011;60:311-6.

2. De Backer G, Ambrosioni E, Borch-Johnsen K, Brotons C, Cifkova R, Dallongeville J, et al. European guidelines on cardiovascular disease prevention in clinical practice. Third Joint Task Force of European and Other Societies on Cardiovascular Disease Prevention in Clinical Practice. Eur Heart J. 2003:24:1601-10.

3. Shirwany NA, Zou MH. Arterial stiffness: a brief review. Acta Pharmacol Sin. 2010;31:1267-76.

4. Weber T, Auer J, O'Rourke MF, Kvas E, Lassnig E, Berent R, et al. Arterial stiffness, wave reflections, and the risk of coronary artery disease. Circulation. 2004;109:184-9.

5. Vlachopoulos C, Aznaouridis K, Stefanadis C. Prediction of cardiovascular events and all-cause mortality with arterial stiffness: a systematic review and meta-analysis. J Am Coll Cardiol. 2010;55:1318-27.

6. Laurent S, Boutouyrie P, Asmar R, Gautier I, Laloux B, Guize L, et al. Aortic stiffness is an independent predictor of all-cause and cardiovascular mortality in hypertensive patients. Hypertension. 2001;37:1236-41.

7. Gaszner B, Lenkey Z, Illyes M, Sarszegi Z, Horvath IG, Magyari B, et al. Comparison of aortic and carotid arterial stiffness parameters in patients with verified coronary artery disease. Clin Cardiol. 2012:35:26-31.

8. Kim HJ, Nam JS, Park JS, Cho M, Kim CS, Ahn CW, et al. Usefulness of brachial-ankle pulse wave velocity as a predictive marker of multiple coronary artery occlusive disease in Korean type 2 diabetes patients. Diabetes Res Clin Pract. 2009;85:30-4.

9. Morice MC, Serruys PW, Sousa JE, Fajadet J, Ban Hayashi E, Perin M, et al. A randomized comparison of a sirolimus-eluting stent with a standard stent for coronary revascularization. N Engl J Med. 2002;346:1773-80.

10. Babapulle MN, Joseph L, Belisle P, Brophy JM, Eisenberg MJ. A hierarchical Bayesian meta-analysis of randomised clinical trials of drug-eluting stents. Lancet. 2004;364:583-91.

11. Cassese S, Byrne RA, Tada T, Pinieck S, Joner M, Ibrahim T, et al. Incidence and predictors of restenosis after coronary stenting in 10004 patients with surveillance angiography. Heart. 2014;100:153-9.

12. Moses JW, Kipshidze N, Leon MB. Perspectives of drug-eluting stents: the next revolution. Am J Cardiovasc Drugs. 2002;2:163-72.

13. Milewski K, Zurakowski A, Pajak J, Pajak-Zielinska E, Liszka L, Buszman PP, et al. Comparison of thin-strut cobalt-chromium stents and stainless steel stents in a porcine model of neointimal hyperplasia. Med Sci Monit. 2010;16:40-4.

14. Ueda H, Hayashi T, Tsumura K, Yoshimaru K, Nakayama Y, Yoshikawa J. The timing of the reflected wave in the ascending aortic pressure predicts restenosis after coronary stent placement. Hypertens Res. 2004;27:535-40.

15. Nakayama Y, Tsumura K, Yamashita N, Yoshimaru K, Hayashi T. Pulsatility of ascending aortic pressure waveform is a powerful predictor of 
restenosis after percutaneous transluminal coronary angioplasty. Circulation. 2000;101:470-2.

16. Mahfouz RA, Abdulmoneim A, Abduo M, Elawady W. The relation of aortic stiffness and in-stent restenosis in patients undergoing percutaneous coronary stenting. Echocardiography. 2013;30:582-7.

17. Fraker Jr TD, Fihn SD, Chronic Stable Angina Writing C, American College of C, American Heart A, Gibbons RJ, et al. 2007 chronic angina focused update of the ACC/AHA 2002 guidelines for the management of patients with chronic stable angina: a report of the American College of Cardiology/American Heart Association Task Force on Practice Guidelines Writing Group to develop the focused update of the 2002 guidelines for the management of patients with chronic stable angina. J Am Coll Cardiol. 2007;50:2264-74.

18. Sianos G, Morel MA, Kappetein AP, Morice MC, Colombo A, Dawkins K, et al. The SYNTAX Score: an angiographic tool grading the complexity of coronary artery disease. Eurolntervention. 2005:1:219-27.

19. Baulmann J, Schillings U, Rickert S, Uen S, Dusing R, Illyes M, et al. A new oscillometric method for assessment of arterial stiffness: comparison with tonometric and piezo-electronic methods. J Hypertens. 2008;26:523-8.

20. Yamashina A, Tomiyama H, Arai T, Hirose K, Koji Y, Hirayama Y, et al. Brachial-ankle pulse wave velocity as a marker of atherosclerotic vascular damage and cardiovascular risk. Hypertens Res. 2003;26:615-22.

21. Liao J, Farmer J. Arterial stiffness as a risk factor for coronary artery disease. Curr Atheroscler Rep. 2014;16:387.

22. Ede H, Erkoc MF, Okur A, Erbay AR. Impaired aortic elasticity and diastolic functions are associated with findings of coronary computed tomographic angiography. Med Sci Monit. 2014;20:2061-8.

23. Liu CS, Li Cl, Shih CM, Lin WY, Lin CH, Lai SW, et al. Arterial stiffness measured as pulse wave velocity is highly correlated with coronary atherosclerosis in asymptomatic patients. J Atheroscler Thromb. 2011;18:652-8.

24. Imanishi R, Seto S, Toda G, Yoshida M, Ohtsuru A, Koide Y, et al. High brachial-ankle pulse wave velocity is an independent predictor of the presence of coronary artery disease in men. Hypertens Res. 2004;27:71-8.

25. Cho SW, Kim BK, Kim JH, Byun YS, Goh CW, Rhee KJ, et al. Non-invasively measured aortic wave reflection and pulse pressure amplification are related to the severity of coronary artery disease. J Cardiol. 2013;62:131-7.

26. Zieman SJ, Melenovsky V, Kass DA. Mechanisms, pathophysiology, and therapy of arterial stiffness. Arterioscler Thromb Vasc Biol. 2005;25:932-43.

27. Strauss BH, Robinson R, Batchelor WB, Chisholm RJ, Ravi G, Natarajan MK, et al. In vivo collagen turnover following experimental balloon angioplasty injury and the role of matrix metalloproteinases. Circ Res. 1996;79:541-50.

28. Chung IM, Gold HK, Schwartz SM, Ikari Y, Reidy MA, Wight TN. Enhanced extracellular matrix accumulation in restenosis of coronary arteries after stent deployment. J Am Coll Cardiol. 2002;40:2072-81.

29. Osherov AB, Gotha L, Cheema AN, Qiang B, Strauss BH. Proteins mediating collagen biosynthesis and accumulation in arterial repair: novel targets for anti-restenosis therapy. Cardiovasc Res. 2011:91:16-26.

30. Ueda H, Nakayama Y, Tsumura K, Yoshimaru K, Hayashi T, Yoshikawa J. Inflection point of ascending aortic waveform is a powerful predictor of restenosis after percutaneous transluminal coronary angioplasty. Am J Hypertens. 2002:15:823-6.

31. Farb A, Sangiorgi G, Carter AJ, Walley VM, Edwards WD, Schwartz RS, et al. Pathology of acute and chronic coronary stenting in humans. Circulation. 1999;99:44-52

32. Li C, Cantor WJ, Nili N, Robinson R, Fenkell L, Tran YL, et al. Arterial repair after stenting and the effects of GM6001, a matrix metalloproteinase inhibitor. J Am Coll Cardiol. 2002;39:1852-8.

\section{Submit your next manuscript to BioMed Central and we will help you at every step:}

- We accept pre-submission inquiries

- Our selector tool helps you to find the most relevant journal

- We provide round the clock customer support

- Convenient online submission

- Thorough peer review

- Inclusion in PubMed and all major indexing services

- Maximum visibility for your research

Submit your manuscript at www.biomedcentral.com/submit
Biomed Central 